existence of disease is an argument only against those who would question the benefit of medical research per se. The ethical issues raised by human gene therapy, insofar as they are distinguishable from the broader discussion of medical ethics, surely cannot be addressed by an appeal to extant human suffering.

This is followed by a clear and concise introduction to the science of genetics and the therapeutic implications of current research. These sections could be read profitably by anyone not familiar with contemporary developments and the scientific background to them. They are well written, accompanied by clear illustrations and the technical vocabulary is kept to a minimum. The first chapter deals with background Mendelian and postMendelian theory. Subsequent chapters are structured on the basis of what the authors refer to as the "conceptual distinctions" (page xvii) between somatic and germ line gene therapy and "between the prevention, treatment, cure of a disease, on the one hand, and enhancement of human characteristics or capabilities, on the other (page xvii). The fact that the authors acknowledge this latter set of distinctions as problematic, yet at no point make any sustained effort to expand upon this, prevents the work from moving beyond the level of a "whistle stop tour" of the issue. The authors argue that there is little substantively new raised by somatic therapy and even germ line techniques, and thus any difficulties can be effectively dealt with on the basis of control by public and expert opinion and codes governing submission of patients, such as the US National Institute of Health (NIH), Recombinant DNA Advisory Committee's Points to Consider (appendix D: 171-85).

In chapter four, we enter the area of enhancement therapy. This is where the most significant ethical issues arise and it is here that the strengths and weaknesses of the authors' treatment become most apparent. What we are offered is a wide-angled view both of the practical possibilities and the concomitant problems. It is the avoidance of abstract speculation in favour of laying out the facts that characterises the book. Anyone reading it for an indepth discussion of either technological or ethical issues is likely to be disappointed.

Were the book to be used for teaching purposes it would need careful handling as there are points at which the authors' eagerness to address as much as possible leads to what can only be viewed as flaws in the argument. For instance, very little attention is given to what must be a central (if not the central) issue: the control and allocation of resources. While this is clearly not something unique to genetically based therapies, if we accept, with the authors, that this is a vitally important area of medicine, then some reassurances need to be given that any benefits will be divided in the most equitable manner. What attention they do pay to the topic is limited to the idea that it ought to be something decided by appropriate legislation and quasialgorithmic codes of practice within a laissez-faire framework, perhaps modified by social and political mores. Conversely, the authors do little to assuage genuine public concerns regarding potential misuses. The spectre of eugenics hangs heavy over the whole field and while we may concur with the writers' assertions that the immorality of previous programmes lay in the immorality of their perpetrators, it is surely little comfort to be told that the impatience of tyrants, combined with the strength of democratic institutions will protect us (page 86). Given the obvious attraction of genetic therapy, absolute control over its allocation would be a welcome addition to any despot's arsenal. Neither would it necessitate the overthrow of parliamentary democracy to foresee a situation in which unscrupulous employers pressurised their workers into undergoing genetic therapy to reduce their desire for sleep, something the authors tell us is well within the realms of possibility (pages 114-5).

Bearing all this in mind the book could, with appropriate supplementation, become a valuable addition to a teaching programme. It would require a substantially longer and more detailed work to begin addressing some of the more profound problems that recombinant DNA therapy raises. It is to be hoped that we do not have to wait a further ten years for its appearance.

RICHARD PAUL HAMILTON Department of Philosophy, The University of Manchester

\section{Complementary Medicine and the Law}

Julie Stone and Joan Mathews, Oxford, Oxford University Press, 1996, 306 pages, $£ 30.00$ hc, $£ 12.99 \mathrm{sc}$.
The rise of complementary medicine in the United Kingdom poses a range of ethical issues for legislators and for the existing bodies regulating medical practice and professions associated with medicine. Some of these issues are particularly sensitive, as in the case with "ethnic medicine", where cultural sensitivities are involved. Most of us would accept that the government has a right (indeed, a duty) to regulate the availability of substances sold as drugs, but does this right extend to the exercise of control over what may be used by the practitioners of Chinese medicine who use substances which fall outside the range of conventional medicines? Some of these imported substances are adulterated with dangerous additions and are capable of harming the patients. Yet to regulate their use may be seen as insensitive to a claimed right of minority communities to pursue their own therapies in their own manner.

The authors of this exceptionally useful survey of the legal position of complementary medicine tackle this and related issues with tact. They are sensitive to the fundamental dilemma facing those who would subject complementary medicine to more rigorous control: such control, even if necessary to avoid the causing of harm by untrained and possibly unscrupulous practitioners, risks placing the complementary therapies in a straitjacket. The whole point of complementary medicine is that it pursues its goals in a way which differs from conventional medicine. Its resources, too, may be idiosyncratic; it may be difficult to prove the efficacy of a herbal remedy in the same way in which one may prove the efficacy of a Western drug. Clinical trials may not make sense in a system in which the practitioner is using a substance as part of the holistic treating of a patient. And then, of course, some remedies may defy the mechanistic notions of contemporary science. Can homoeopathic remedies possibly work in their extraordinary dilutions? Conventional science would answer that this is impossible, and yet homoeopathic practitioners point to the results they achieve as an indication that something is happening which conventional science may not be able to explain. For many believers in complementary therapies, the arguments used against them make sense only within a system of scientific explanation which they question. They resent 
being measured, and possibly regulated, according to a yardstick which they see as self-validating and oppressive.

The position of the United Kingdom government on the regulation of complementary medicine has been described as one of "benevolent neutrality". There is an interesting discussion in this book of how this policy has been translated into a legislative response. In some cases it has led to professionalisation and greater regulation - producing, for example, statutory regulation of chiropractic. The authors point out that this is probably inevitable, in the case of activities that can do real harm, but they are concerned that in respect of other therapies there may be a tendency to choose a professional model in order to secure privilege. The law, Stone and Mathews suggest, is fundamentally ill-suited to deal with most complementary therapies, which are best regulated by ethical principles voluntarily endorsed by practitioners who would regulate qualifications and conduct. Such a scheme always leaves room for the charlatans and the fraudsters - who could practise outside the registered bodies - but one might wonder whether these are an inevitable feature of freedom of choice. In a highly regulated world, the opportunities for risk or harm are diminished, but so too are the opportunities for experimentation or for individual self-fulfilment. Paternalism may have a legitimate role, but it is a very small role which must be watched with great caution. On this point, it is interesting that the authors see the political danger for complementary medicine as emanating to a great extent from the European Union. There are certainly those within that structure who would like to regulate and harmonise a wide range of targets, and if there is a real threat to freedom of choice in health matters it might well prove to come from that quarter.

This is an excellent, scholarly work which contains a great deal of useful information on the legal and ethical aspects of an increasingly important subject. It should start an interesting debate on issues which have not previously been given their due in medical ethics and medical law.

ALEXANDER McCALL SMITH Professor Medical Law, Faculty of Law, University of Edinburgh
The Treatment of Ethics in a Swedish Government

\section{Commission on Gene Technology} Birgitta Forsman and Stellan Welin,
Gothenburg, Centre for Research Ethics, 1995, 42 pages, US $\$ 15.00$.

The starting point of this study is the fact that "scientists have often stated, in popular contexts such as media interviews, that biotechnology 'demands' that ethical matters be considered. Politicians have also expressed this view" (page 1). The authors of this report "wanted to have a closer look at the alleged 'need' for ethics. What needs have appeared? What does cognition about and attitudes towards ethics look like? What role is ethics supposed to play, and what role has it hitherto played in Sweden?" (page 1). The study focuses on a white paper from a Swedish government commission. It is a book with the title Genteknik - en utmaning (Gene technology - a challenge) (- Statens Offentliga Utredningar, Swedish official commission - SOU 1992:82). The central source for the study is this white paper (SOU 1992:82) and besides that unpublished papers connected to the white paper. A few interviews have also been done with some key persons, experts on the commission. The interviewees were regarded mainly as informants.

The use of official commissions in Sweden by the government is very common and the purpose is to provide a basis for legislation. The commission on gene technology was set up to consider several problems and the main focus of this study is: ethical principles for what should be permitted and forbidden in the use of gene technology. The commission decided not to deal with gene technology and human beings. That subject had already been treated in a white paper in 1984 .

Three of the experts on the commission were ethicists and one of them had formulated a certain kind of ethical analysis as a basis for decisionmaking. This was to help the members of the commission to question their spontaneous moral views in favour of more reflective views. The scheme presented was "embraced by the commission, but in a very vague way", and it was used "but in a very rudimentary way" (page 11). The $\stackrel{\square}{\varrho}$ commission also dealt with values in a $\vec{F}$ normative way, but it was "limited and rudimentary and the choice of the value basis seems to have been very $\overrightarrow{\vec{F}}$ arbitrary" (page 12). The authors of the report give some examples of this $\frac{\mathrm{C}}{\mathrm{O}}$ and conclude by saying: "Presumably, $\frac{\bar{\omega}}{\overline{0}}$. the belief - or hope - of the commission was that people with the 'right' $\mathbb{\varrho}$ attitudes do not perform morally wrong acts. The commission seems to $\rightarrow$ have resorted to a motive oriented? ethics" (page 13).

The commission often returned to $\omega^{\omega}$ two principles: the doctrine of environmental protection and the rever- $\widehat{\Phi}$ ence for life principle. They did not ${ }_{\mathcal{E}}$ explain why. It seems the commission os used various different principles, but $\dot{\omega}$ they nowhere state why they preferred $\stackrel{\infty}{\mathcal{O}}$ the principles they used. The commis- $ᄋ$ sion focused on moral issues but when they tried to make ethical reflections $\square$ based on moral problems they seemed ${ }^{\mathbb{D}}$ to be groping in the dark. The sugges- $\Phi$ tions the commission made did not $\frac{3}{6}$ follow from the premises contained in the value base they had, arbitrarily, $\vec{\bullet}$ chosen. The only philosophere mentioned in the white paper was. Immanuel Kant, but the authors \&f the report thought it would have been interesting to see not only Kant's view applied, but also the views of some

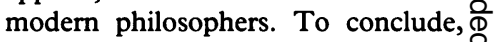
the authors are very critical of how the commission treated the ethical aspects of gene technology.

An interesting question is of course why the ethical aspects were treated in? this amateurish way despite the fact that the commission had three ethi- $\overparen{\Phi}$ cists as experts to help them. The chapter in the white paper about $\underline{3}$. ethics was written by one of the secretaries who had no background in either ethical or philosophical studies. 0 And there does not seem to have been? much discussion between the ethicists $\frac{D}{0}$ and the members of the commission. Then what did the ethicists con- $N$ tribute? One of them "talked mostly about forms and procedures for $N$ obtaining reasonable ethical decisions". Another "talked about val- 0 ues". And the third one "seems to have said very little at all" (page 22). None of them made any objections to the commission's conclusions in the white paper and the representatives $\frac{\overrightarrow{0}}{0}$ for the government were very satisfied $\underset{\mathbb{D}}{\stackrel{0}{*}}$ with the white paper and stated that $\stackrel{\square}{\mathscr{Q}}$ "ethics had been seriously con- $\mathbb{Q}$ sidered" (page 24).

Reasonable questions then, after reading this report, are whether there is 